\title{
THE FUTURE OF MAPPING - 3D MAPS, THE COMPARISON OF TWO OF THE MOST USED METHODS IN PHOTOGRAMMETRIC FIELD
}

\author{
Iuliana Cuibac Picu $^{\text {a, }}{ }^{*}$, P. Dragomir ${ }^{c}$, R. Peters ${ }^{\text {d }}$ \\ a, b * National Center of Cartography, Cartography and Photogrammetry Department, 012101 / Doctoral School, Technical University \\ of Civil Engineering of Bucharest, 020396, Romania, e-mail: iuliana.cuibac@cngcft.ro \\ ${ }^{\mathrm{c}}$ Faculty of Geodesy, Topography and Cadastre Department, Bucharest, Romania \\ ${ }^{\mathrm{d}}$ Department of Urbanism, Faculty of Architecture and the Built Environment, TU Delft, The Netherlands, e-mail: r.y.peters@tudelft.nl
}

Received: 30.05.2020 / Accepted: 10.06.2020/ Revised: 06.09.2020 / Available online: 15.12.020

DOI: 10.2478/jaes-2020-0018

KEY WORDS: 3D maps, stereo-restitution, extrusion, geodatabase, footprint, 3D model, LiDAR.

\begin{abstract}
:
In the last 15 years, mapping technology has become a necessity in smart cities planning. And $2 \mathrm{D}$ are starting to be augmented by $3 \mathrm{D}$ maps. 3D Maps are already used in the cartographic field, to create a three-dimensional view of the terrain and buildings. In this paper we address the concept of 3D Maps and we compare two methods to generate such maps. In this study two 3D maps were built, one using photogrammetric 3D stereo-restitution and one using automatic extrusion from a LiDAR point cloud and a set of 2D vector polygons. Upon comparison of these maps, we have concluded that the accuracy of the two maps is very similar and it depends very much on the input data and we have observed that creating a precise 3D map in photogrammetric environment takes much longer than the one built using the LiDAR point cloud. As 3D maps become the future of mapping, there is a continuous need for more accurate and complete field data to be collected and processed. Once more detailed field data becomes available, a clear conclusion on which of the methods provide us with a more accurate 3D map could be drawn. The evolution of 3D mapping is rapidly growing together with the applications developed to use it, especially in surveying and material monitoring. The key to future development of smart cities in based on better designs and infrastructures, and 3D mapping technology is a vital instrument to assist such a development.
\end{abstract}

\section{INTRODUCTION}

In recent years, more engineers and architects all over the world have approached the relatively new field of three-dimensional modelling of a study area, preferring 3D design systems to the classic 2D drawing systems (Yan, 2012). The final results is a 3D map with a complex textures structure having different layers for each object such as roads, buildings, trees (http://www.marketwatch.ro/articol/2275). Finally, the data obtained can be integrated and exported in other specialized programs for different fields of activity such as design, urban planning, tourism, real estate, police and security (Neusch, 2002). In the current period of urbanization and industrialization growth, for an urban area, there is a real need for adequate urban planning, automation and for new techniques used for urban planning. 3D models of urban areas are essential for many applications, such as military operations, disaster management, mapping of buildings and their heights, simulation of new buildings, updating and storage of cadastral data, change detection and virtual reality (Tse, 2008). In most of these cases, building models, urban characteristics, land area and vegetation are the principal features of interest
In the late 1960s the concept of stereo-restitution was first introduced in the photogrammetric field, and after that, this technique used to create 3D maps, became a known area widely utilized (Mali, 2012).

The most accurate, fast and versatile measurement technique is LiDAR (Light Detection and Ranging) (Jadhav, 2009). With this data, 3D models of the city and beyond can be obtained using the Extrusion method. 3D models start with data acquisition by laser scanning, followed by grading point clouds by eliminating noise, modelling point clouds and the final step consists of merging with a 2D data set (footprint) to create a 3D map (http://www.lidar-uk.com/usage-of-lidar/). LiDAR (light and ramp detection) data is a relatively new technology for obtaining digital surface models (DSM) of the earth's surface (Kuželka, 2020). Various researchers are developing methods for automatically extracting functions, either from LiDAR or from the combination of LiDAR and digital images for creation / use and comparison in a GIS environment (Jadhav, 2009).

This paper analyses and compares two 3D maps obtained, one using stereo-restitution and the other using extrusion from a ground footprint obtained using 2D digitization on orthophoto maps and a LiDAR point cloud.

\footnotetext{
* Corresponding author: Iuliana Cuibac Picu, National Center of Cartography, Cartography and Photogrammetry Department, 012101 / Doctoral School, Technical University of Civil Engineering of Bucharest, 020396, Romania, e-mail: iuliana.cuibac@cngcft.ro.
} 
Stereo-plotting is an accurate technique that provides 3D observation but requires specific photogrammetric knowledge and equipment (Soile, 2015) like a 3D cursor. In the same way, the points necessary for 3D modelling are extracted, or it draws the contour lines to represent the relief (https://www.theotop.ro/ STEREORESTITUTIE-C4/).

\section{TYPES OF METHODS}

\subsection{Stereo restitution}

Stereo restitution is the photogrammetric method of visualizing 3D models of an area, obtained from aerial images, and their linear details with the help of a special 3D cursor, generating the digital map of the area in vector format, editable with mapping software. In the same way, it extracts the points to generate the level curves for the representation of the relief (https://www.theotop.ro/STEREORESTITUTIE-C4/).

The method is creating a depth in overlapping images (Figure 1) by using binocular vision (https://en.wikipedia.org/ wiki/Stereoscopy).

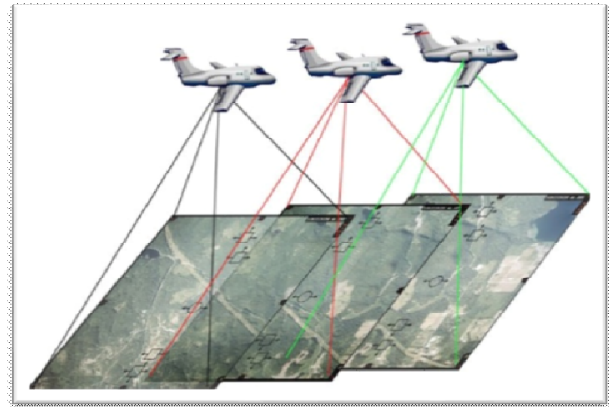

Figure 1. Overlapping images

(https://www.slideshare.net/waleedliaqat/lecture-on-photogrammetry)

Nowadays the photogrammetry software is designed to work with images captured by DSLR cameras. There are even applications that can be installed on mobile devices, allowing the user to create 3D maps using just an iPad (https://3dinsider.com/3d-mapping-cameras/). The result is a faithful reproduction of the $3 \mathrm{D}$ area, without any parallax, ie the end result for a single observation is a stereoscopic 3D image (Figure 2) (Biljecki, 2017). External instruments, such as 3D glasses, a special cursor (topo-mouse) and a 3D monitor are needed to generate, view and measure objects in a stereoscopic environment (Petrie, 2001).

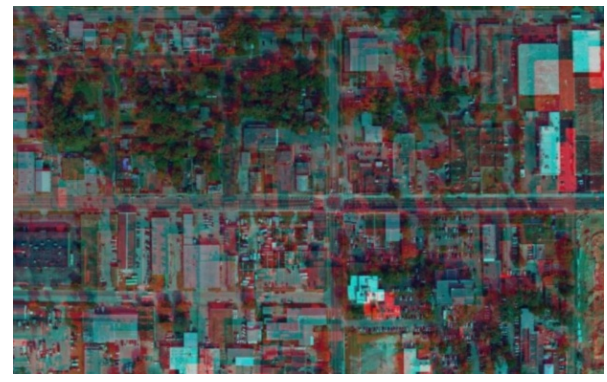

Figure 2. Stereoscopic image for an urban area (https://www.gisresources.com/evolving-photogrammetry-single-pairstereo-multi-view-raycloud)
The workflow (Figure 3) for obtaining a stereo-model is the same as the one for a photogrammetry project, starting with the data acquisition and ending with the map's generation. The results of the workflow are split in 2 maps in different format, a 3D Map in vector format and a 2D Map in raster format, also called the ortho images.

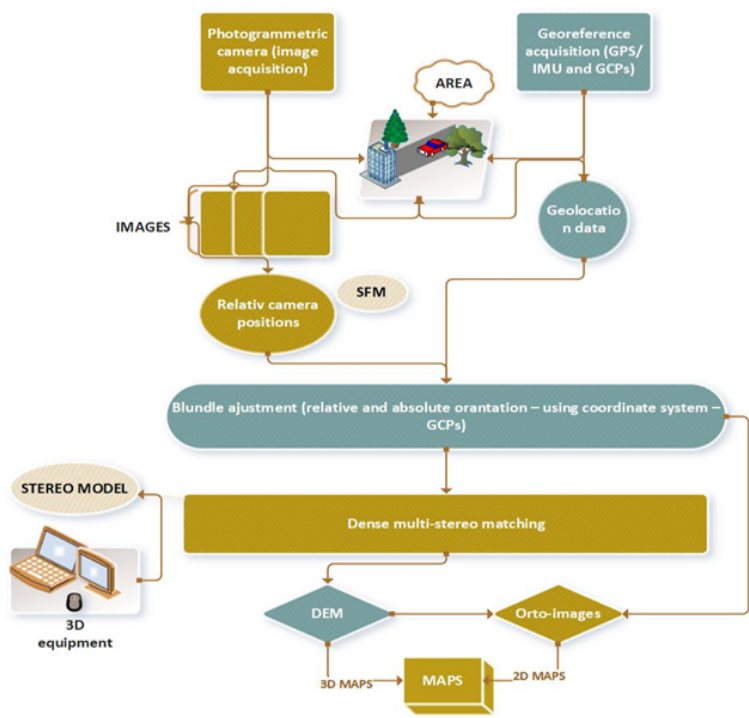

Figure 3. Photogrammetry workflow

In conclusion, the method bases conventional 3D stereoscopic techniques on the use of two or more overlapping images containing one or more common objects and parallax (resulting from landforms) related to the elevation of the terrain until it produces the required depth (https://www.sciencedirect. com/topics/earth-and-planetary-sciences/orthophoto). The result is also a geodatabase use for $2 \mathrm{D}$ maps, how contains all the features extracted.

\subsection{Extrusion}

In this article, the 3D model of the test area was determined using data from airborne laser scanning (LiDAR) using extrusion (Haala, 2008). This method involves the characteristics of objects in vector and $2 \mathrm{D}$ format, obtained by a digitization of the ortho images lifted to a single height creating volumetric 3D city models. Usually, the heights are obtained from LiDAR (e.g. the average elevation of all points within a footprint), from a cadastral database, or from a volunteered geo information, for example using the number of floors (Vitalis, 2019).

Although the method is simple (buildings so-called LOD1 models), it offers a lot of advantage over the 2D datasets and can be used for shadow analysis and line-of-sight predictions. In conclusion, although simple (Figure 4), the method raises some challenges regarding the errors in the $2 \mathrm{D}$ data, which will propagate to the generated 3D model, also the calculation of the height of each terrain feature can be relatively slow, because the process use TIN construction and simplification (http://tudelft3d.github.io/3dfier/). For the building features the process is quite fast. 


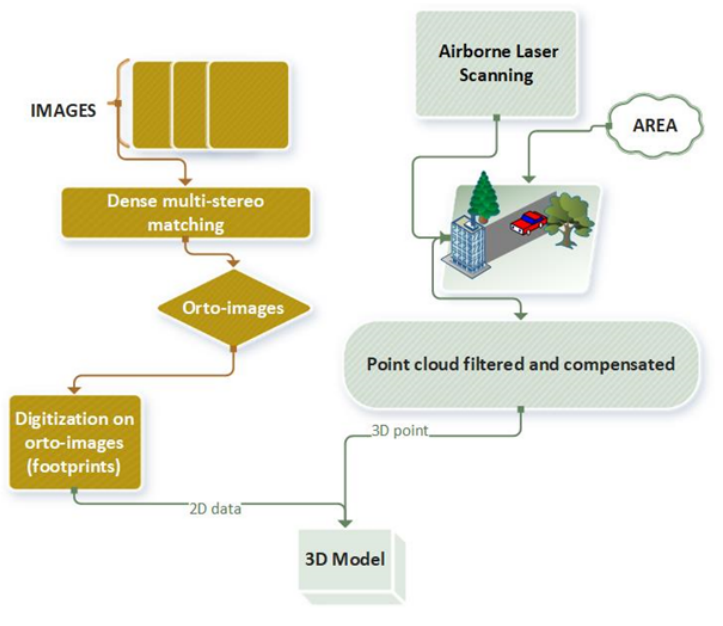

Figure 4. Extrusion method using LiDAR and images

\section{CASE STUDY}

\subsection{Test area}

For the test area (Figure 5) a village was chosen from a European project LAKI II (http://www.ancpi.ro/LAKI 2/), an area called Tulca. Tulca is in Bihor County, Crisana, Romania, comprising the villages of Căuașd and Tulca (the residence). It has a total planimetric area of $56.87 \mathrm{~km}^{2}$.

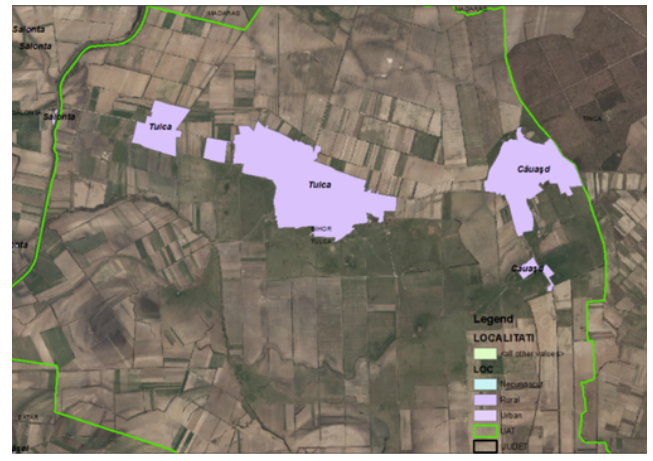

Figure 5. Test area

\subsection{Case study}

In this study case, the results achieved by comparing two 3D maps of the same area, obtained by using 2 different approaches, will be analysed. To create the 3D map, two original sources of data were used, digital airborne images and a LiDAR point cloud. We can find below the input data, the corresponding products obtained and the result of the comparisons using the two different approaches.

To generate this map, a photogrammetric station was used, which includes a 3D monitor, a special 3D cursor and the most important connected equipment, the 3D glasses. With the stereo display, the $3 \mathrm{D}$ depth given by at least 2 overlapping images is perceived and thus it was possible to collect 3D features from the stereo images of the formed block (Table 1).

\begin{tabular}{|l|l|}
\hline \multicolumn{1}{|c|}{ Longitudinal coverage } & \multicolumn{1}{c|}{60} \\
\hline Transverse coverage & 30 \\
\hline Orthorectified image accuracy & $20 \mathrm{~cm}$ \\
\hline Spatial resolution & $20 \mathrm{~cm}$ \\
\hline
\end{tabular}

Table 1. The image parameters

The photogrammetric block was created in the ERDAS Extension for the ArcGIS Software. For the digitization of the 3D measurement in the stereo model the StereoAnalist for Arcgis extension was used. The geodatabase was created considering of the next table, known from the technical specifications of the European LAKI II project (Table 2).

\begin{tabular}{|l|l|}
\hline $\begin{array}{l}\text { Geometry } \\
\text { type }\end{array}$ & \multicolumn{1}{c|}{ Requirement } \\
\hline Line & $\begin{array}{l}\text { A line must be represented by one or more } \\
\text { connected vectors. }\end{array}$ \\
\hline Polygon & $\begin{array}{l}\text { A polygon must be represented by three or } \\
\text { more vectors: }\end{array}$ \\
\hline & $\begin{array}{l}\text { The starting point must be identical (3D) to } \\
\text { the end point (3D). }\end{array}$ \\
& $\begin{array}{l}\text { The perimeter of a polygon object cannot } \\
\text { intersect itself (it cannot have common 2D or } \\
\text { 3D points) }\end{array}$ \\
\hline $\begin{array}{l}\text { A polygon must have a positive value area. } \\
\text { Minimum surface limits (area) are specified } \\
\text { for certain object classes. }\end{array}$ \\
\hline $\begin{array}{l}\text { Curves, } \\
\text { Circles }\end{array}$ & $\begin{array}{l}\text { Must not exist. All objects must be points or } \\
\text { composed of vectors }\end{array}$ \\
\hline
\end{tabular}

Table 2. 3D objects of geodatabase

When a stereo pair was loaded, the Stereo view displayed two images in which the epipolar lines are parallel to the $\mathrm{x}$-axis. The $3 \mathrm{D}$ cursor always returns to $\mathrm{x}, \mathrm{y}$ and $\mathrm{z}$, which were displayed in the current projection units, in our case in meters since we used Stereographic projection 70 . In case of missing vertical data, the $\mathrm{z}$ unit is taken the same as the one defined in the data set for creating the orthophotomap, and the resulting data is $2 \mathrm{D}$. All data that formed an object in the model contains $3 \mathrm{D}$ coordinates $(\mathrm{X}, \mathrm{Y}, \mathrm{Z})$, in meters (Table 3).

\begin{tabular}{|c|c|c|c|}
$\begin{array}{c}\text { Ground } \\
\text { Sample } \\
\text { Distance }\end{array}$ & $\begin{array}{c}\text { Planimetric } \\
\text { accuracy }\end{array}$ & $\begin{array}{c}\text { Altimetric } \\
\text { accuracy }\end{array}$ & $\begin{array}{c}\text { Point } \\
\text { deviation } \\
\text { in space }\end{array}$ \\
\hline $20 \mathrm{~cm}$ & $30 \mathrm{~cm}$ & $30 \mathrm{~cm}$ & $45 \mathrm{~cm}$ \\
\hline
\end{tabular}

Table 3. The 3D maps errors

These operations are simple to perform but the completion of the 3D map takes a minimum of 2 month to complete this small area (Figure 6). The final product is a geo database as presented in table 4.

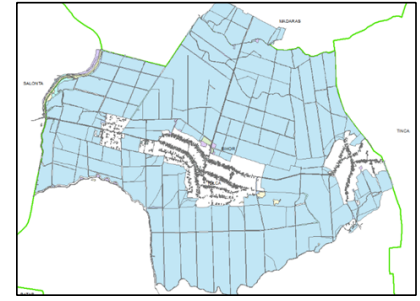

Figure 6. The final 3D Maps from stereo-model 


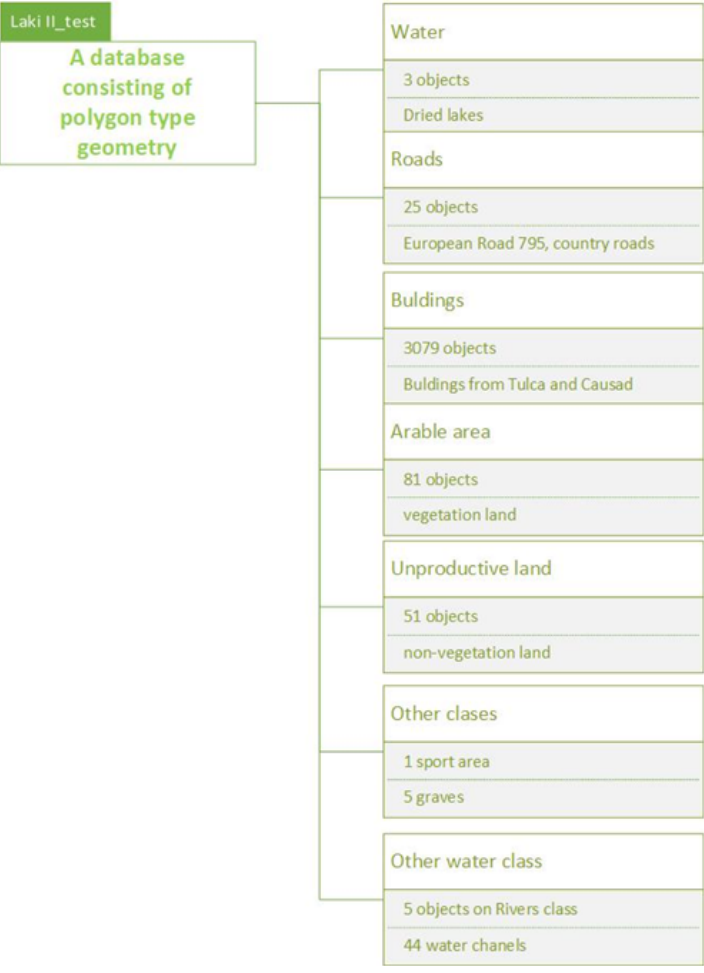

Table 4. The structure of the database

In this second part of the study case we have created 3D Maps using a 2D data topographic map called TopRo 5, a land cover map and a LiDAR point cloud, from the same European project LAKI II. TopRo 5 is the Romanian map database. We have extracted from that database only the polygons features: roads, houses, vegetation, water and soil. From the LAKI II project, the point cloud was in the LAS format and projected to the National Reference System Stereo 70 and the Black Sea 75. We classified the point cloud into 3 classes: soil, unclassified and noise class.

For the parts in the study area that were not covered by objects from the national TopRo 5 database, we created new polygons in the QGIS software (Figure 7), with the same classes as the geodatabase from airborne images.

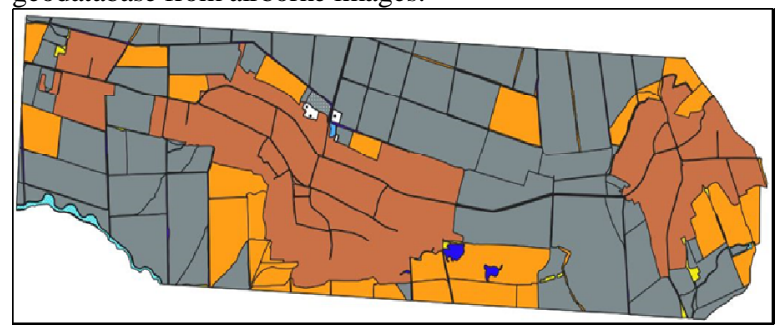

Figure 7. The 2D vector data

We classified the point cloud (Figure 8) in the classes related to the objects found in the 2D data (buildings, soil, vegetation, water, unclassified). The classification was automatically done in ERDAS Imagine2018, using the parameters shown in Table 5 .

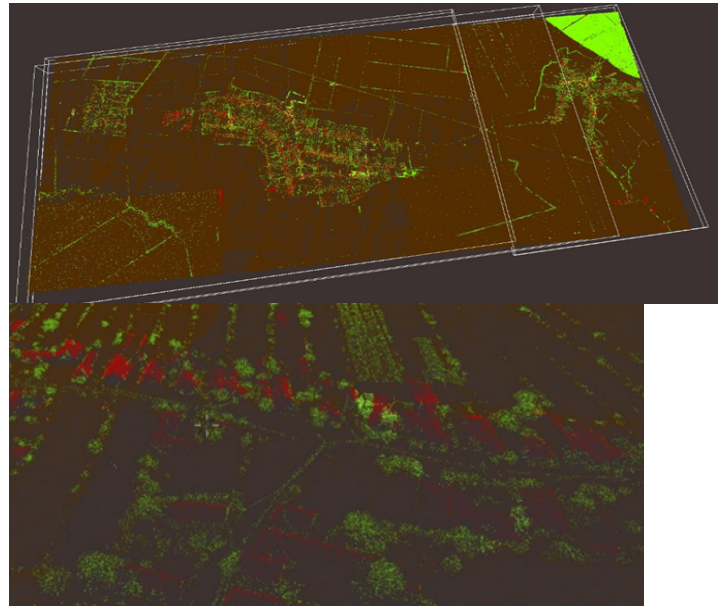

Figure 8 . The classified point cloud

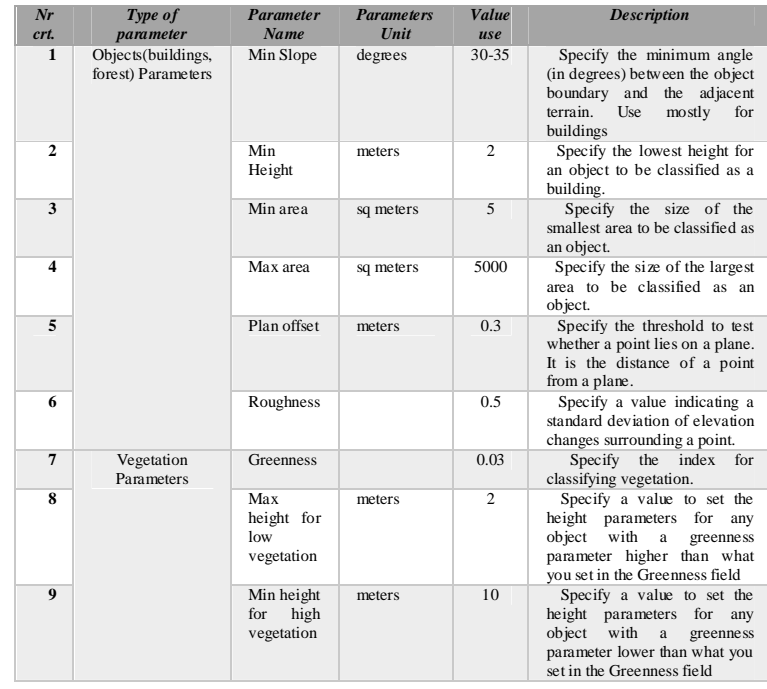

Table 5. The classification parameters

We used the 3dfier software to make the 3D Map. This software takes the polygon features from the $2 \mathrm{D}$ data map and the classified LiDAR point cloud and raises each polygon to the corresponding 3D height. We created the data configuration file (Figure 9) according to the specifications in the software documentation, adding the variables according to the test data set, considering the topographic database and the point cloud. If the cloud wasn't classified, all point cloud classes had to be used. It was necessary to define the level of detail for buildings ( 0 and 1 possible). The result had no visible errors (Figure 10), and it was obtained in obj format and viewable using the MesLab software (https://www.meshlab.net/), open source software.

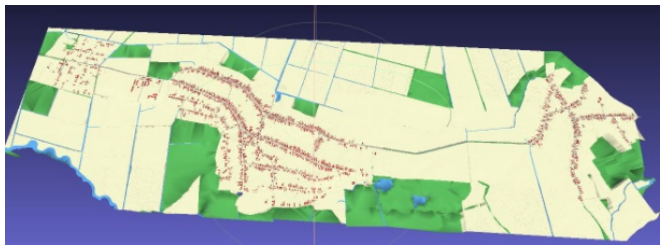

Figure 10. The 3D Map from the point cloud 


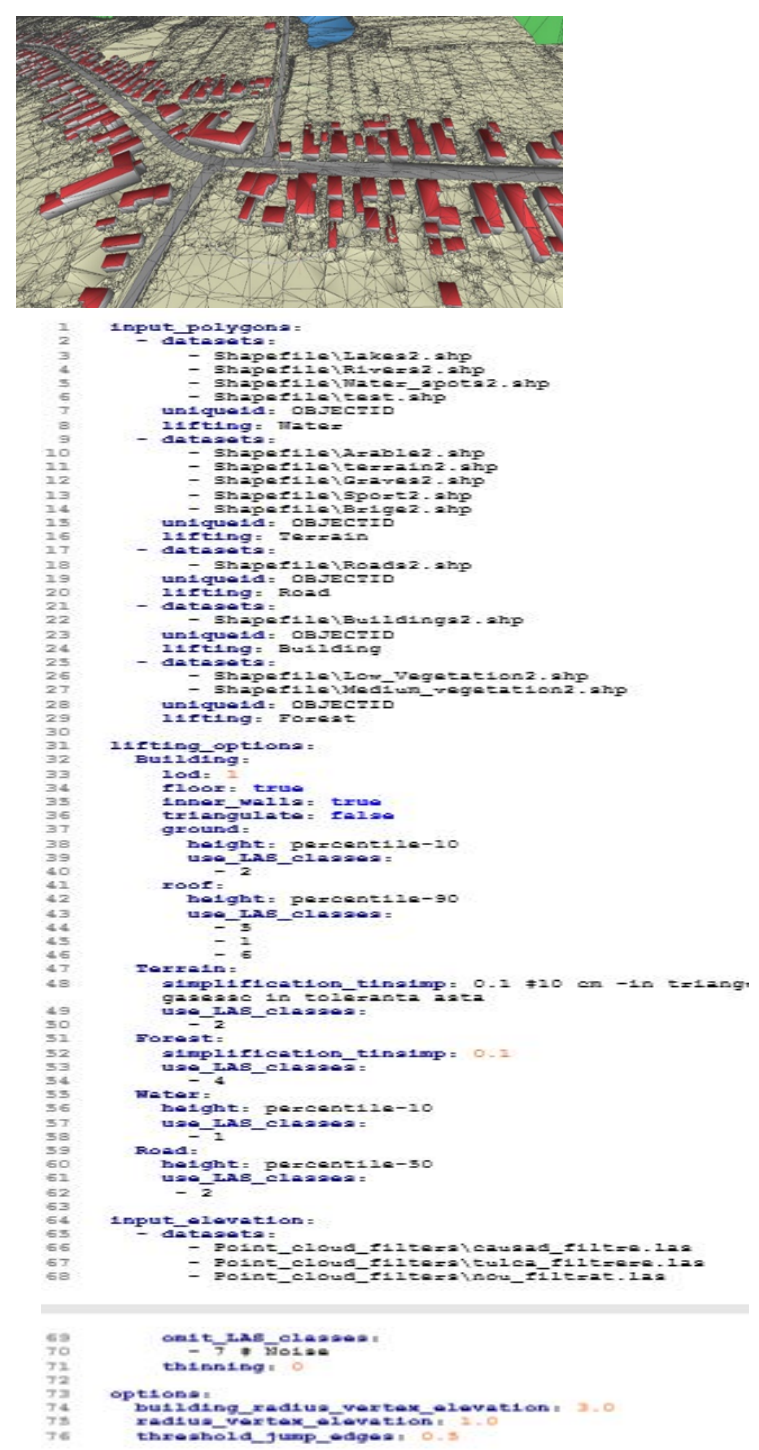

Figure 9. The data configuration file in the command line

In order to demonstrate that the 3D map obtained from the point cloud is more precise and the method represents a much faster way to obtain the desired results, we perform a comparison between the two obtained results. We made this comparison in the MeshLab software. Calculating the geometric difference between the two 3D models is quite a common task in processing this data or mesh data. In the MeshLab software, a standard tool for such a task was developed and distributed. While Metro is a small, open source independent command-line program available on the website, its functionality has been integrated into MeshLab in the Sampling-> Hausdorff Distance filter and can be used in a variety of ways (Straub, 2007).

The parameters used were the numbers of samples, in this case 155398 and the value for the maximum area in meters and percent, 345190 meters and $34.32 \%$.

To compare the two meshes (Figure 11), the 3D map from the stereo-model was transformed into the OBJ format with the help of FME software, licensed Safe software. In this process each feature in the $2 \mathrm{D}$ geodatabase is transformed into a $3 \mathrm{D}$ object with the OBJ extension.

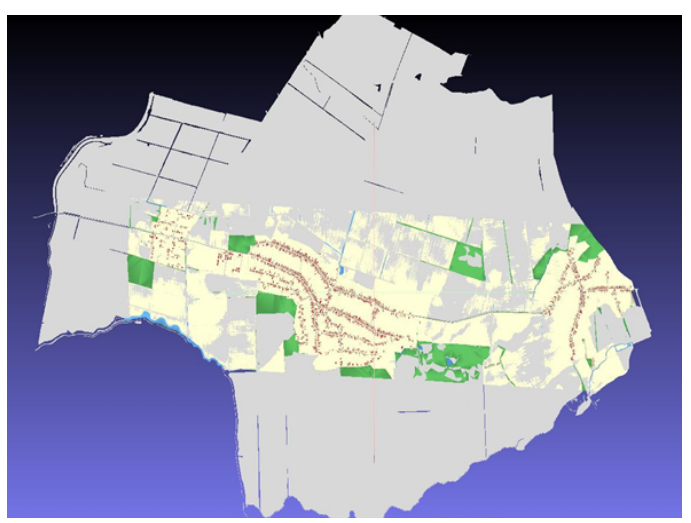

Figure 11 . The 2 mesh of the 3D data

After merging all the separate OBJ files, the two 3D products were compared in order to observe the difference and the accuracy of the data. The result is a point cloud where each point stores a distance that was computed between the two 3D products. In the areas where there is no information in the reference set, no comparison has been done. The summary of the comparison is shown in next table (Table 6) and in the image below (Figure 12).

\begin{tabular}{|l|l|}
\hline \multicolumn{2}{|c|}{ Hausdorff Distance Result } \\
\hline No. of points & 5137338 \\
\hline RMS of the merged point cloud & 33.804977 \\
\hline Maxim Errors & 0.031173 \\
\hline Mean errors & 0.001897 \\
\hline RMS - the final error & 0.004503 \\
\hline
\end{tabular}

Table 6. The parameters results

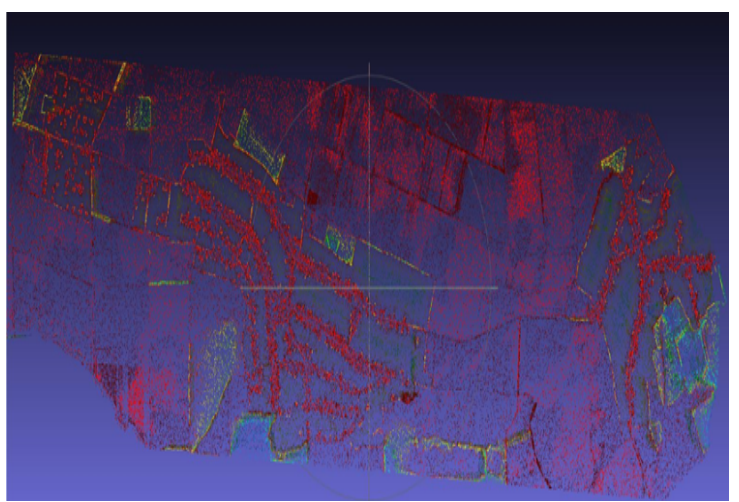

Figure 12. The visual results 
The comparison result is that the small distances are shown in red and large distances in blue.

\section{CONCLUSIONS}

The method using conventional 3D stereoscopic techniques is based on the use of two or more overlapping images containing one or more common objects and parallax (resulting from landforms) related to the elevation of the terrain until it produces the required depth. To generate a map in a 3D environment, you need to have at you disposal, besides the designated software, auxiliary equipment such as $3 \mathrm{D}$ monitor, 3D glasses and 3D mouse.

With the ever-increasing availability of overlapping stereoimagery gained in digital form from airborne and the software to visualize and measure, the benefits of $3 \mathrm{D}$ stereo-viewing $3 \mathrm{D}$ map generation can be experienced by ever more people working in the geo informatics field.

The software company representatives have in plan to ease the usage of 3D stereo-viewing of the terrain with all the advantages that go with it. Although it is becoming easier to digitize a map in a $3 \mathrm{D}$ environment, this procedure still requires a long time for a final precise product to be obtained. With a precise digital topographic map and a point cloud classified with high accuracy, the digital 3D model of the terrain can be created in just a few minutes. The 3D model of the different areas has only 4 classes (road, land, building, water and forest), these can be enlarged by adding distinct classes of vegetation by creating a script and adding it to the 3 dfier software.

The accuracy of the result depends very much on the data input. The result may be in a different format depending on the software and the application in which the data is intended to be used. Contemplating the visual result, we can conclude there are not so many errors, and the maps have about the same accuracy. We can see larger differences and errors in areas with lakes and on the edge of villages. We can conclude that the point cloud classification and the precision with which the objects were digitized affects the of the 3D map. After comparing the two 3D models, we conclude that there is a need for more data from the field to assist us in drawing the conclusion on which of the two $3 \mathrm{D}$ maps is the most accurate.

\section{ACKNOWLEDGEMENTS}

The authors thank the National Centre of Cartography for providing the aerial imagery and the point cloud, the colleagues from the University of Delft - Department of Urbanism, Faculty of Architecture and the Built Environment, TU Delft, The Netherlands, partners in the VOLTA project (Grant Agreement no. 734687 - VOLTA - H2020-MSCA-RISE-2016) who provided with the FME licenses used for the transformation process and for the use of the 3DFIER.

\section{References:}

Biljecki, F., Ledoux, H., Stoter, J., 2017. Generating 3D city models without elevation data. Computers, Environment, and Urban Systems, 64: $1-18$.

Haala, N., Petera, M., Kremerb, J. and Hunter, G., 2008. Mobile Lidar Mapping for 3D Point Cloud Collection in Urban Areas - a Performance
Test. Proceedings of XXI ISPRS Congress, Beijing, China, July 3-11, 37.

Kuželka, K., Slavík, M. and Surov, P., 2020. Very High Density Point Clouds from UAV Laser Scanning for Automatic Tree Stem Detection and Direct Diameter Measurement. Remote Sens., 12, 1236; doi: 103390/rs12081236.

Mali, S., Panhalkar, S., Pawar, C. and Das, S., 2012. Generation of 3-D City Model for Urban Utility Information System Using Digital Photogrammetry \& GIS Technology. Global Journal of Researches in Engineering Volume XII Issue VIII Version I.

Neusch, T., Grussenmeyer, P., 2002. Urban Imagery combining Photogrammetric and Remote Sensing Techniques: a New Training Course at Ensais Strasbourg. The International Archives of the Photogrammetry, Remote Sensing and Spatial Information Sciences, Vol. XXXIV, Part 6, CVI.

Petrie, G., 2001. 3D Stereo-Viewing of Digital Imagery: Is AutoStereoscopy the Future for 3D?. GEOInformatics. 4. 24-29.

Soile, S., Verykokou, S., and Ioannidis, C., 2015. Stereo-orthoimage as a GIS tool for reliable restitution of Cultural. International Journal of Heritage in the Digital Era volume 4 number 3+4.

Vitalis, S., Ohori, K. A. and Stoter, J., 2019. Incorporating Topological Representation in 3D City Models. ISPRS International Journal of GeoInformation. 8(8):347, DOI: 10.3390/ijgi8080347.

Yan, T., Rynson, W. H. L., Xu, Y., 2012. Depth Mapping for Stereoscopic Videos. Int J Comput Vis (2013) 102:293-307 DOI 10.1007/s11263-012-0593-9.

Tse, R. (O.C.), Gold, C., and Kidner, D., 2008. 3D City Modelling from LIDAR Data. Chapter 10, Advances in 3D Geoinformation Systems pp 161-175.

http://www.marketwatch.ro/articol/2275/Model_3D_al_orasului_model ul\%20viitorului/ (The 3D model of a modern future city (RO)) (visited in 15-20 June 2020).

https://www.theotop.ro/STEREORESTITUTIE-C4/ (visited in 01-10 August 2020).

https://pro.arcgis.com/en/pro-app/help/analysis/image-analyst/stereomap.htm (visited in 01-15 August 2020).

Jadhav A., Gambhir D., 2009. Use of LiDAR in Extraction of 3D City Models in Urban Planning. https://www.geospatialworld net/article/useof-lidar-in-extraction-of-3d-city-models-in-urban-planning/ (visited in 01-15 august).

https://www.slideshare.net/waleedliaqat/lecture-on-photogrammetry (visited in 01-15 August 2020).

https://en.wikipedia.org/wiki/Stereoscopy (vi sited in 15 Julie 2020).

https://3dinsider.com/3d-mapping-cameras/ (visited in 16 Julie 2020).

https://www.gisresources.com/evolving-photogrammetry-single-pairstereo-multi-view-raycloud/ (visited in 17 Julie 2020).

https://www.sciencedirect.com/topics/earth-and-planetarysciences/orthophoto (visited 02 August 2020).

http://tudelft3d.github.io/3dfier/ (visited on 22 Julie 2020).

http://www.ancpi.ro/LAKI 2/ (visited on 17 August 2020).

https://github.com/tudelft3d/3dfier/tree/master/docs (visited on 23 August 2020).

Straub R., 2007. Exact Computation of the Hausdorff Distance between Triangular Meshes. https://publikationen.bibliothek.kit.edu/1000027274 (visited in 30 August 2020).

http://www.lidar-uk.com/usage-of-lidar/ (visited in 28 August 2020).

https://www.meshlab.net/ (visited in 20 August 2020). 